\title{
Distinctive Impact Pattern of Ak 47/56 Projectile on Glass Fracture
}

\author{
Waghmare NP* \\ Forensic Science Laboratory, India
}

Submission: April 19, 2018; Published: May 10, 2018

*Corresponding author: Waghmare NP, Forensic Science Laboratory NCT of Delhi, Madhuban Chowk Sector-14, Delhi-110085, India, E-mail: npwaghmare@rediffmail.com

Abstract

Glass is present everywhere in our society. Because of its fragile nature, we see it often as evidence in violent crime as well as in burglaries and shootings. Hence, it is not surprise that glass sheet may be encounter as intermediate target during shooting encounter between low enforcement agencies and criminals. In such cases use of AK 47/56, 303, .315,SLR rifles and revolver, pistol as handguns may not be ruled out. Microscopic glass fragments retrieved from scenes of crime; one collected, can be compared to a potential source of the glass. Glass bends in response to any force that it exerted on any one of its surface; when the limit of its elasticity is reached, the glass fractures. frequently, fractured window glass will reveal information that can be related to the force and direction of the impact; such knowledge may be useful for reconstructing events at a crime-scene investigation.

In present paper, impact of $7.62 \times 39 \mathrm{~mm}$ fully jacketed bullet of AK-47/56 on glass fracture have been studied because of most of terrorist groups are using this type of rifles for doing terror attacks in the society. Different aspects of glass fracture have been explained in respect of characteristics impact pattern of glass fracture. It was observed that, effect of high velocity bullet on glass sheet would exhibit a round clean hole, beveled occurring outward at exit side. It was also observed the crack branching of a bifurcation occurs only when the applied stress is sufficient high. Findings of these data may be useful in crime investigation. New findings on fracture of glass sheet by jacketed bullet of AK47/56 rifle have been investigated.

Keywords: AK-47/56 assault rifle; Ammunition; Glass fracture; High-speed impact

\section{Introduction}

In criminal investigation it is well known fact that, glass targets may influence the distribution of projectile fragments in shooting case of fatal injuries by regular as well as fatal rifle. During shooting encounters between criminal and police variety of object like glass, ceramic, window screens, vehicles, wall and articles of clothing etc. served as intermediate targets for bullet May ricochets bullet or it may become secondary missiles. The penetration of ordinary window glass by a projectile, whether it is a bullet or a stone, produces a familiar fracture pattern in which cracks both radiate outwards and encircle the hole. Frequently it is difficult to determine just from the size and shape of a hole in glass whether it was made by a bullet or by some other projectile. For example, a small stone thrown at a comparatively high speed against a pane of glass will often produce a hole very similar to that produced by a bullet. On the other hand, a large stone can completely shatter a pane of glass in a manner closely resembling the result of a close-range shot.

But in later case, the presence of gunpowder deposits on the shattered glass fragments does point to damage caused by a firearm. In literature survey, various methods are available for examination and comparison of glass fragments. The variation of in size of glass sheet have a significant influence on the resultant fracture of glass was described by O'Hara and Osterburge [1]. Gamble et al. [2]. Remaining velocity of bullet fired through glass plate was estimated Johari et al. [3]. Interpretation of mode of glass fracture arises by bullet impact, in terms of dynamical stress filed were explained Nag et al. [4]. When it penetrate glass, a high velocity projectile such as bullet often leaves a round, crater shaped hole that is surrounded by a nearly symmetrical pattern of radial and concentric cracks. The hole is inevitable wider at the exit side and hence its examination is an important factor in determining the direction of impact.

However, as the velocity of the penetrating projectile decreases, the irregularity of the shape of the hole and of its surrounding cracks increases so that at some point the whole shape will provide no assistance for determining the direction of impact. At this time, information derived from an examination of the radial and concentric fracture lines may prove a useful 
alternative for determining the direction of impact. The perforation craters created on glass sheet had always a well defined shape with more or less constant semi angle which were independent of the projectiles caliber, velocity and thickness of target materials [5]. Hackle marks are also found on the roughened surface surrounding the fracture hole [6]. Generally a small arms bullet is cylinders conical in shape and endowed with a high rate of spine. When such bullet passing through a glass target. It makes a considerable difference and modified the basic values of various parameters as reported by Burred [7]

The implications of forensic problems of the manner in which a float glass surface beak was also well described by Thorton et al. [8]. FBI laboratory followed their reports of evidence of fractured glass in criminal investigation [9]. Examination of glass fracture from forensic point of view was explained by Tryhorn [10]. Finally detailed discussion on nature of glass fracture as an aid in the solution of forensic issues was observed by Grass [10]. No studies were reported on fracture of glass sheet by impact of various bullets in forensic point of view. Attempts have been made to analyze the fracture of glass by $7.62 \times 39 \mathrm{~mm}$ jacketed bullet and its significance at the crime scene. Alert notes to crime scene manager police officer have been also suggested. This analytical study will help forensic examiners to ascertain the nature of glass fracture. When a force of gas pushes on one side of a pane of glass, the elasticity of the glass permits it to bend in the direction of the force applied. Once the elastic limit is exceeded, the glass begins to crack. The first fractures form on the surface opposite that of the penetrating force and these fractures develop into radial lines. The continued motion of force places tension on the front surface of the glass resulting in the formation of concentric cracks.

\section{Materials and Method}

A specially designed metal frame having one feet by feet size was used to hold glass pane of 1'x1'. This frame was attached on the steel frame for ground support. The proposed metal frame was kept perpendicular to the muzzle end of firearms. Firearm was fix in voice which is fixed on heavy carrying wooden table. Metal frame to keep glass sheet kept in frame so that after each firing, glass sheet can be removed and replaced easily. The firing arrangement is shown in fig. 1 the fully jacketed bullets of $7.62 \times 39 \mathrm{~mm}$ with $146 . \mathrm{g}$ rains in weight of propellant, length of bullet is $29.46 \mathrm{~mm}$ with sharp pointed in shape were successfully test fired through glass sheet and as a resulted glass fracture were measured, analyzed and interpreted as shown in Figure $1 \& 2$.

\section{Result and Discussions}

When full jacketed bullet of $7.62 \times 39 \mathrm{~mm}$ caliber passes through an ordinary commercial glass sheet, fracture distribute up to a long distance from the penetration hole. It was observed that fracture produced by AK47/56 projectile vary from those developed by blunt impact, irrespective of striking energy. The craters generated as a result from the impact of a projectile may give important information concerning the type of projectile use. It was observed, if the applied stress is low after reducing the powder charge from the ammunition, fracture occurs without crack branching and the fracture of glass surface appears very smooth. The characteristic of key hole pattern on target are not present in regular firearm (Figures 1 \& 2). Figure 2 illustrated a regular fracture surface around the fracture holes obtained. The smooth area obtained around the bullet holes on glass surface called the mirror surface appears about the fracture initiating flow.

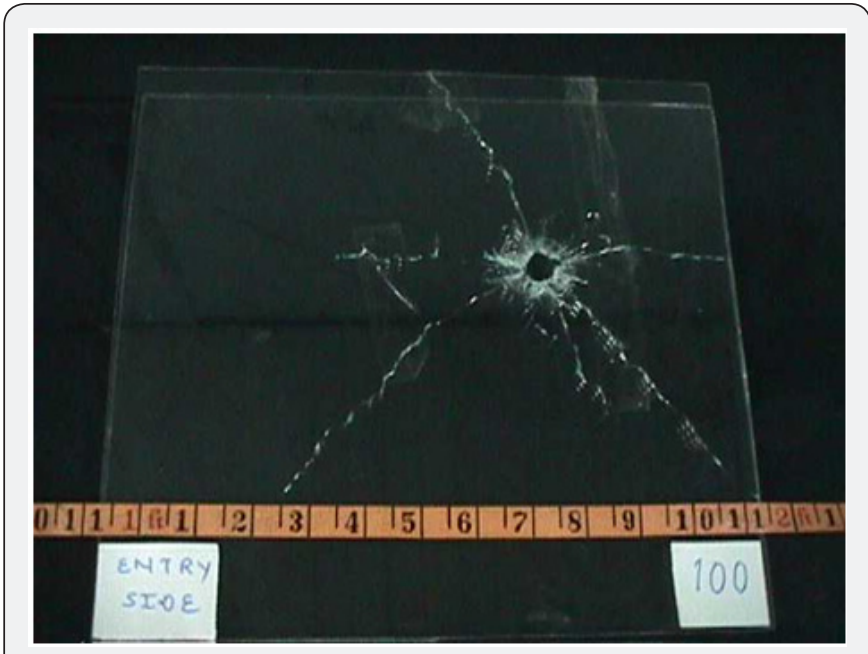

Figure 1

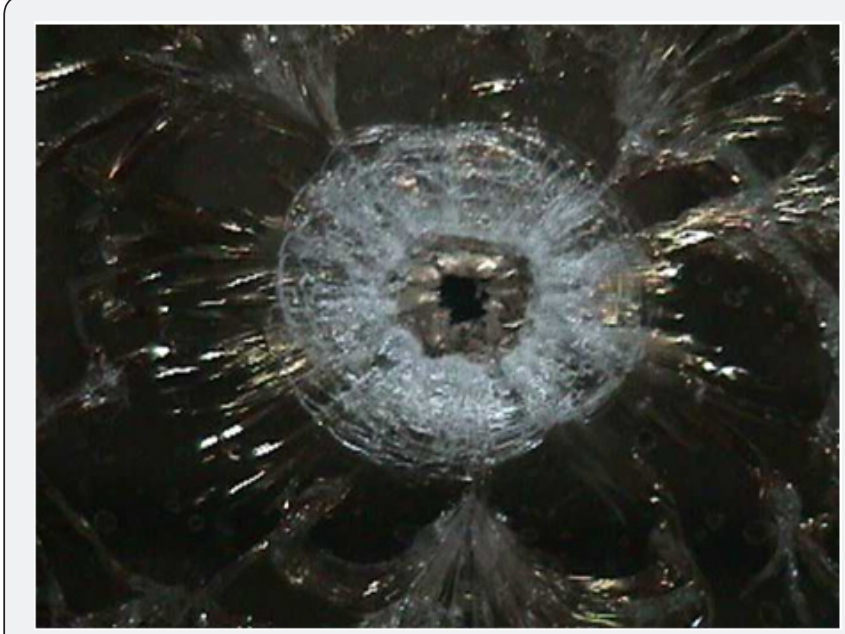

Figure 2

This pattern is bounded by the mist zone which showed the beginning of microscopic crack branching the inner mirror radius. The fracture surface area on glass sheet showed a highly rough area called the hackle region. Impact of AK-47/56 jacketed bullet on glass sheet causes glass fracture having characteristics features depends on the velocity, firearms and angle of impact (Ref Tables $1 \& 2$ ). It is also revealed that there is no change in irregularity of glass sheet hole if velocity of AK-47/56 assault 
rifle changed up to ascertain limit such as up to five meters from the study of the holes. It is observed that concentric patterns around the hole emanate from the edge of the bullet hole which are formed early in the fracture process. Afterwards the radial fractures are created. These observations are very useful at places of occurrence. Our findings also aggress with the theory of beveling phenomena at exit. Waller lines showed that they are a series of marking concave towards the fracture origin. Hence, these lines may be useful to indicate the direction of crack propagation.

Table 1

\begin{tabular}{|c|c|c|c|c|c|c|c|c|c|}
\hline Sl.No. & $\begin{array}{c}\text { Radial } \\
\text { fracture }\end{array}$ & $\begin{array}{l}\text { Concentric } \\
\text { fracture }\end{array}$ & Rib markis & $\begin{array}{l}\text { Hackle } \\
\text { marking }\end{array}$ & $\begin{array}{l}\text { Mirror } \\
\text { surface }\end{array}$ & $\begin{array}{c}\text { Mist zone } \\
\text { edge }\end{array}$ & $\begin{array}{l}\text { Wallner } \\
\text { lines }\end{array}$ & $\begin{array}{c}\text { Heartzean } \\
\text { lines }\end{array}$ & $\begin{array}{c}\text { Petal } \\
\text { pattern }\end{array}$ \\
\hline 1 & Present & Present & Present & Present & Present & Absent & Present & Present & Absent \\
\hline 2 & Present & Present & Present & Present & Present & Absent & Present & Present & Absent \\
\hline 3 & Present & Present & Present & Present & Present & Absent & Present & Present & Absent \\
\hline 4 & Present & Present & Present & Present & Present & Absent & Present & Present & Absent \\
\hline 5 & Present & Present & Present & Present & Present & Absent & Present & Present & Absent \\
\hline 6 & Present & Present & Present & Present & Present & Absent & Present & Present & Absent \\
\hline 7 & Present & Present & Present & Present & Present & Absent & Present & Present & Absent \\
\hline 8 & Present & Present & Present & Present & Present & Absent & Present & Present & Absent \\
\hline 9 & Present & Present & Present & Present & Present & Absent & Present & Present & Absent \\
\hline 10 & Present & Present & Present & Present & Present & Absent & Present & Present & Absent \\
\hline 11 & Present & Present & Present & Present & Present & Absent & Present & Present & Absent \\
\hline 12 & Present & Present & Present & Present & Present & Absent & Present & Present & Absent \\
\hline 13 & Present & Present & Present & Present & Present & Absent & Present & Present & Absent \\
\hline 14 & Present & Present & Present & Present & Present & Absent & Present & Present & Absent \\
\hline 15 & Present & Present & Present & Present & Present & Absent & Present & Present & Absent \\
\hline 16 & Present & Present & Present & Present & Present & Absent & Present & Present & Absent \\
\hline 17 & Present & Present & Present & Present & Present & Absent & Present & Present & Absent \\
\hline
\end{tabular}

1.Type of glass sheet: Commercial glass sheet

2. Thickness of glass sheet: $4 \mathrm{~mm}$
3. Glass position of target: Build in condition

4. Firearm used: AK-47 assault rifle.

Table 2: Data of Glass Fracture by AK-47/56 bullet.

\begin{tabular}{|c|c|c|c|c|}
\hline Sl.No. & $\begin{array}{c}\text { Average radius of mirror } \\
\text { zone (from center of glass } \\
\text { hole) in inch }\end{array}$ & $\begin{array}{c}\text { Average radius of mist zone } \\
\text { (from center of glass hole } \\
\text { in inches) }\end{array}$ & $\begin{array}{c}\text { No. of concentric } \\
\text { lines }\end{array}$ & $\begin{array}{c}\text { No. of petal present } \\
\text { around the glass note }\end{array}$ \\
\hline 1 & 0.386 & Absent & 03 & Absent \\
\hline 2 & 0.533 & Absent & 03 & Absent \\
\hline 3 & 1.51 & Absent & 03 & Absent \\
\hline 4 & 0.463 & Absent & 05 & Absent \\
\hline 5 & 0.525 & Absent & 03 & Absent \\
\hline 6 & 0.437 & Absent & 03 & Absent \\
\hline 7 & 0.256 & Absent & 03 & Absent \\
\hline 8 & 0.161 & Absent & 04 & Absent \\
\hline 9 & 1.097 & Absent & 03 & Absent \\
\hline 10 & 0.547 & Absent & 03 & Absent \\
\hline 11 & 0.565 & Absent & 03 & Absent \\
\hline 12 & 0.545 & Absent & 03 & Absent \\
\hline 13 & 0.524 & Absent & 03 & Absent \\
\hline 14 & 0.512 & Absent & 03 & Absent \\
\hline 15 & 0.521 & Absent & 03 & \\
\hline
\end{tabular}


The edges of the radial and concentric cracks frequently reveals stress markings whose shape can be related to the side on which the window was first cracked. For concentric fracture, the perpendicular end always faces the surface on which the force originated. These observations may be remembered by thumb 3R rule - Radial Cracks from a Right Angle on the Reverse Side of the Force. These facts will enable the forensic examiner to determine readily the side on which a window was broken. When successive penetrations of glass firing, it is frequently possible to determine the sequence of impact by observing the existing fracture lines and their points of termination. A small arms bullet is cylindro-conical in shape and endowed with a high rate of spin. When such type of bullet traverses a glass target, it makes a considerable difference and modifies the basic values of various parameters. An improvised firearm in which no regular rifling is present in the barrel achieves less velocity.

Hence, if we applied stress is low, fracture occurs without crack branching and the fracture surface appears very smooth as is often observed for the thermal fracture of glass. Interestingly, keyhole effects were present on windowpane in the test firings of improvised pistol. These characteristics could not be present in regular firearm firearms. It may be due to their impact of high velocity. In .303", .315", 7.62x51mm, 7.62x39mm ammunition key hole effect observed on each of the target. Experimental result revealed that the fracture mirrors, wallner lines, rib marks and hackle mark are very important clues to investigate that the fracture of origin and crack propagation direction of float glass as well as the fundamental interpretation of the fracture. In general, a crack does not immediately change its direction when an applied force inclined to the surface of a running crack is applied. In this paper it is showed that the mirror surface region.

Waller lines frequently appear as a result on the interaction between elastic waves produced from some irregularities at the surface such as flaws and the stress at the crack front. Generally Wallner lines are a series of marking concave towards the fracture origin. Therefore, Waller lines can also be applied to indicate the direction of crack propagation. Table- 1 shows that the series of cracks radiate in a star shape pattern which are radial fractures originate from the point of impact but in improvised firing, concentric lines are not found and few numbers of radii at lines formed on the glass sheet. A fracture always terminates at an existing line of fracture Figure 1.

\section{Conclusion}

Glass fracture produced by bullet of AK-47/56 assault rifle is different from other firearms. From the radius of mist/mirror zone, we can know the type of firearms used at crime spot. These are the new finding can be useful in criminal investigation. These observations may be helpful to forensic expert, glass examiners and crime scene manger etc. On the examination of fracture edge rib marking are observed in all cases in radii fractures, rib markings are distributed perpendicular to the surface of impact and tangentially with the opposite surface. However in the concentric region these markings are right angles to his impact surface. In case of Hackle marks are also observed at right angles to rib markings more than hackle markings are found nearer to the point of impact, which traveled in the direction of movement of fracture.

\section{References}

1. O'Hara CE, Osterburgn JW (1949) Criminilstics, The Macmillan Company, new york, pp. 302,334,386.

2. Gamble LH, Burd DO, Kirk PL (1943) Glass Fragments as Evidence," A comparative study of physical properties. J Crim Law and criminology 33(5): 416-421.

3. Jauhari M, Chaterjee SM, Gosh PK (1974) Remaining velocity of bullets fired through glass plates. J Forensic Sci Soc 14(3): 3-7.

4. Nag NK, Sinha P (1960) Ind Acad Forensic Science. 1(1): 43.

5. Frye DA (1957) Unusual Damage to plate Glass windows, Pol J: 344.

6. Burrad G (1951) the identification of Firearms and Forensic Ballistics, London.

7. Burrad G (1955) the modern Shot, London 2: PP253-PP265.

8. Thorton JI, Cashman PJ (1986) Glass Fracture mechanism- A Rethinking. JFS 31(3): 818-824.

9. FBI Federal Bureau of Investigation, (1936), Evidence of fractured glass in criminal investigation, FBI Law Enforcement Bulletin, p.2

10. Grass H (1962) In criminal Investigation (ed.R.Jackson) (5 $5^{\text {th }}$ edn.), Sweet \& Maxwell, New York, USA.

Your next submission with Juniper Publishers will reach you the below assets

- Quality Editorial service

- Swift Peer Review

- Reprints availability

- E-prints Service

- Manuscript Podcast for convenient understanding

- Global attainment for your research

- Manuscript accessibility in different formats

( Pdf, E-pub, Full Text, Audio)

- Unceasing customer service

Track the below URL for one-step submission https://juniperpublishers.com/online-submission.php 